\title{
AN AMENABILITY PROPERTY OF ALGEBRAS OF FUNCTIONS ON SEMIDIRECT PRODUCTS OF SEMIGROUPS
}

\author{
BAO-TING LERNER \\ Department of Mathematics \\ U. S. Naval Academy \\ Annapolis, MD 21402
}

(Received March 2, 1982 and in revised form June 28, 1982)

ABSTRACT. Let $S_{1}$ and $s_{2}$ be semitopological semigroups, $S_{1}(T) S_{2}$ a semidirect product. An amenability property is established for algebras of functions on $\mathrm{s}_{1}$ (T) $\mathrm{s}_{2}$. This result is used to decompose the kernel of the weakly almost periodic compactification of $\mathrm{s}_{1}\left(\mathcal{T} \mathrm{s}_{2}\right.$ into a semidirect product.

KEY WORDS AND PHRASES. Semitopological semigroup, semidirect product, compactification, amenability, strongly almost periodic, weakly almost periodic, kernel.

AMS (MOS) subject classifications (1970). Primary 22A15, 22A20, 43A07; Secondary 43460

1. INTRODUCTION. Let $\mathrm{S}_{1}, \mathrm{~S}_{2}$ be semitopological semigroups (in the terminology of Berglund and Hofmann (1)) with identities, each denoted by 1 . That is $\mathrm{s}_{1}$ and $\mathrm{s}_{2}$ have (Hausdorff) topologies relative to which multiplication in $s_{1}$ and $s_{2}$ is separately continuous.

Let $\tau: S_{2} \times S_{1} \rightarrow S_{1}$ be a separately continuous map satisfying for each $s_{1}, t_{1} \varepsilon s_{1}, s_{2}, t_{2} \varepsilon s_{2}, \tau\left(s_{2}, s_{1} t_{1}\right)=\tau\left(s_{2}, s_{1}\right) \tau\left(s_{2}, t_{1}\right), \tau\left(s_{2} t_{2}, t_{1}\right)=$ $\tau\left(s_{2}, \tau\left(t_{2}, t_{1}\right)\right), \tau\left(s_{2}, 1\right)=1$, and $\tau(1, \cdot)$ is the identity map.

We shall assume the map $\left(s_{1}, s_{2}\right) \rightarrow s_{1} \tau\left(s_{2}, t_{1}\right): s_{1} \times s_{2} \rightarrow s_{1}$ is continuous for each $t_{1} \in S_{1}$. The semidirect product $s_{1}$ (T) $s_{2}$ of $s_{1}$ and $s_{2}$ is the topological space 
$s_{1} \times s_{2}$ equipped with multiplication $\left(s_{1}, s_{2}\right)\left(t_{1}, t_{2}\right)=\left(s_{1} \tau\left(s_{2}, t_{1}\right), s_{2} t_{2}\right)$. The above conditions on $\tau$ imply that $S_{1}(T) S_{2}$ is a semitopological semigroup with identity $(1,1)$.

Let $F$ be a closed translation invariant sub- $C^{*}-a$ lgebra of $C\left(\mathrm{~S}_{1}(\tau) \mathrm{S}_{2}\right.$ ) (see $\$ 2$ below) containing the constant functions. In previous papers (2) and (3), the author has formulated the necessary and sufficient conditions for the decomposition of the F-compactification of $\left(\mathrm{S}_{1}(\mathrm{~T}) \mathrm{S}_{2}\right)$, into a semidirect product. The decomposition may be written symbolically as

$$
\left(\mathrm{S}_{1}(\mathrm{~T}) \mathrm{s}_{2}\right)^{\mathrm{F}}=\mathrm{s}_{1}{ }^{\mathrm{G}} \odot \mathrm{s}_{2}{ }^{\mathrm{H}}
$$

where $G=\{f(\cdot, 1): f \varepsilon F\}$ and $H=\{f(1, \cdot): f \varepsilon F\}$ and equality denotes canonical isomorphism ( $\rho$ being another semidirect product).

Applications of this decomposition were then made to the almost periodic (AP), strongly almost periodic (SAP) and left-uniformly continuous (LUC) cases. The situation is less well-behaved in the weak1y almost periodic (WAP) case. For example, if $s_{1}=s_{2}$ is any commutative topological semigroup with identity for which $\operatorname{WAP}\left(\mathrm{S}_{1}\right)=\operatorname{AP}\left(\mathrm{S}_{1}\right)$, then (1.1) fails even if $\mathrm{S}_{1} \odot \mathrm{S}_{2}$ is taken to be the special case of a direct product (Junghenn (4)).

However, in the present paper we shall prove an amenability property of algebras of functions on $S_{1}(T) S_{2}$ which generalizes a result of Junghenn (5) and provides conditions under which the kernel of the WAP-compactification of $\mathrm{s}_{1}$ (T) $\mathrm{s}_{2}$ can be decomposed into a semidirect product.

2. PRELIMINARIES. Throughout this section $\mathrm{S}$ denotes a semitopological semigroup and $\mathrm{C}(\mathrm{S})$ the $\mathrm{C}^{*}$-algebra of bounded continuous complex-valued functions on $\mathrm{S}$. We define operators $R_{t}$ and $L_{s}$ on $C(S)$ by

$$
R_{t} f(s)=f(s t)=L_{s} f(t) \quad(s, t \varepsilon s ; f \varepsilon \quad C(s))
$$

Let $\mathrm{F}$ be a conjugate closed, norm closed linear subspace of $\mathrm{C}(\mathrm{S})$ containing the constant function 1 . Then $F$ is right (resp. left) translation invariant if $R_{S} F \subset F$ (resp. $\left.L_{S} F \subset F\right)$; translation invariant if it is both left and right translation invariant.

A mean on $F$ is a positive linear functional $\mu$ in $F^{*}$, the dual of $F$, such that $\mu(1)=1=\|\mu\|$. We denote by $M(F)$ the set of all means on $F$. A mean $\mu$ 
on $F$ is multiplicative if $\mu(f g)=\mu(f) \mu(g), f, g \varepsilon F$. We denote the set of all multiplicative means on $\mathrm{F}$ by $\mathrm{MM}(\mathrm{F})$.

If $\mathrm{F}$ is left (resp. right) translation invariant, then a mean $\mu$ is left (resp. right) invariant if, for each $f \varepsilon F$, $s \in S$, we have $\mu\left(L_{s} f\right)=\mu(f)\left(\operatorname{resp}_{s} \mu\left(R_{s} f\right)=\right.$ $\mu(f))$. The set of all jeft (resp. right) invariant means on $F$ shall be denoted by $\operatorname{LIM}(F)$ (resp. RIM(F)). F is left (resp. right) amenable if $\operatorname{LIM}(F) \neq \emptyset$ (resp. $\operatorname{RIM}(F) \neq \emptyset)$. If $F$ is translation invariant and both left and right amenable, $\mathrm{F}$ is called amenable.

Now suppose $F$ is left translation invariant. For each $\nu \varepsilon F^{*}$ define $\mathrm{T}_{\nu}: \mathrm{F} \rightarrow \mathrm{C}(\mathrm{S})$ by $\left(\mathrm{T}_{\nu} \mathrm{f}\right)(\mathrm{s})=\nu\left(\mathrm{L}_{\mathrm{s}} \mathrm{f}\right)$, $\mathrm{f} \varepsilon \mathrm{F}, \mathrm{s} \varepsilon \mathrm{s}$. Then $\mathrm{F}$ is left introverted if $T_{\nu} F C F$ for each $\vee \varepsilon M(F)$. If $F$ is an algebra, then $F$ is left-m-introverted if $\mathrm{T}_{\nu} \mathrm{F} \subset \mathrm{F}$ for each $\nu \in \mathbb{M}(\mathrm{F})$. Right introversion and right-m-introversion are defined in an analogous manner.

If $F$ is a sub-C* - algebra of $C(S)$ then $S^{F}$ denotes the spectrum (=space of nonzero continuous complex homomorphisms) of $F$ equipped with the relativized weak ${ }^{*}$ topology, and $e: S \rightarrow S^{F}$ the evaluation mapping.

If $\mathrm{F}$ is admissible (i.e. $\mathrm{F}$ is translation invariant, left-m- introverted, containing the constant functions) then a binary operation $(x, y) \rightarrow$ my may be defined on $S^{F}$ relative to which the pair $\left(S^{F}, e\right)$ has the following properties:

(i) $\mathrm{S}^{\mathrm{F}}$ is a compact Hausdorff topological space and a semigroup such that for each $y \in S^{F}$, the mapping $x \rightarrow x y: S^{F} \rightarrow S^{F}$ is continuous;

(ii) $e: S \rightarrow S^{F}$ is a continuous homomorphism with range dense in $S^{F}$ such that for each $s \in S$, the mapping $x \rightarrow e(s) x: S^{F} \rightarrow S^{F}$ is continuous; and (iii) $e^{*} C\left(S^{F}\right)=F$.

The pair $\left(S^{F}, e\right)$ is the canonical F-compactification of $S$.

Let $\mathrm{K}(\mathrm{S})$, called the kernel of $\mathrm{S}$, denote the minimal ideal of $\mathrm{S}$. We sha11 use the amenability property in the next section to decompose the kernel of the WAPcompactification of $\mathrm{S}_{1}$ (T) $\mathrm{S}_{2}$ into a semidirect product.

3. THE AMENABILITY THEOREM. Let $\mathrm{s}_{1}$ and $\mathrm{S}_{2}$ denote semitopological semigroups with identities and $\mathrm{S}_{1}\left(\mathcal{T} \mathrm{S}_{2}\right.$ a semidirect product as defined in $\S 1$. We shall denote by 
$\mathrm{q}_{1}: \mathrm{s}_{1}+\mathrm{s}_{1}$ (T) $\mathrm{s}_{2}$ and $\mathrm{q}_{2}: \mathrm{s}_{2}+\mathrm{s}_{1}$ (T) $\mathrm{s}_{2}$ the injection mappings $\left(\mathrm{q}_{1}\left(\mathrm{~s}_{1}\right)=\left(\mathrm{s}_{1}, 1\right)\right.$, $\mathrm{q}_{2}\left(\mathrm{~s}_{2}\right)=\left(1, \mathrm{~s}_{2}\right)$, for $\left.\mathrm{s}_{1} \in \mathrm{s}_{1}, \mathrm{~s}_{2} \varepsilon \mathrm{s}_{2}\right)$. Let $\mathrm{q}_{i}{ }^{*}: \mathrm{C}\left(\mathrm{s}_{1}\left(\mathcal{T} \mathrm{s}_{2}\right) \rightarrow \mathrm{C}\left(\mathrm{s}_{\mathbf{i}}\right)\right.$ denote the dual mapping of $q_{i}, i=1,2$.

THEOREM 3.1

(a) Suppose $\mathrm{F}$ is a left translation invariant, left introverted closed subspace of $\mathrm{C}\left(\mathrm{S}_{1}(\tau) \mathrm{S}_{2}\right)$ containing the constant functions, and the semigroup $D=\left\{s_{2} \in s_{2}: \overline{\tau\left(s_{2}, S_{1}\right)}=s_{1}\right\}$ is dense in $s_{2}$. Then $F$ is left amenable if $q_{1}{ }^{*} F$ and $\mathrm{q}_{2}{ }^{\star} \mathrm{F}$ are left amenable.

(b) Suppose $\mathrm{F}$ is a right translation invariant, right introverted closed subspace of $\mathrm{C}\left(\mathrm{S}_{1}\left(\mathrm{~T} \mathrm{~S}_{2}\right)\right.$ containing the constant functions. Then $\mathrm{F}$ is right amenable if $\mathrm{q}_{1}{ }^{*} \mathrm{~F}$ and $\mathrm{q}_{2}{ }^{*} \mathrm{~F}$ are right amenable.

PROOF. To prove (a) choose any $\mu_{1} \varepsilon \operatorname{LIM}\left(q_{1}{ }^{*} \mathrm{~F}\right)$, and for each $f \varepsilon F$ define (Uf) $\left(s_{2}\right)=\mu_{1}\left(q_{1}^{*}\left(L\left(1, s_{2}\right) f\right)\right), s_{2} \varepsilon s_{2}$.

Then $U: F \rightarrow q_{2}{ }^{\star} F$ : For let $f \varepsilon F$. Since $F$ is left introverted, $T_{\nu} F \subset F, \forall \nu \varepsilon M(F)$ where $\left(T_{\nu} f\right)\left(s_{1}, s_{2}\right)=\nu\left(L_{\left(s_{1}, s_{2}\right)} f\right), f \varepsilon F,\left(s_{1}, s_{2}\right) \varepsilon\left(S_{1} \odot s_{2}\right)$. Observe that

$$
\begin{aligned}
& \text { (Uf) }\left(s_{2}\right)=\mu_{1}\left(q_{1}{ }^{*}\left(L /\left(1, s_{2}\right) f\right)\right)=T\left(\mu_{1}{ }^{\circ} \mathrm{q}_{1}{ }^{*}\right) \mathrm{f}\left(1, s_{2}\right) \\
& =\mathrm{q}_{2}{ }^{*}\left(\mathrm{~T}\left(\mu_{1}{ }^{\circ} \mathrm{q}_{1}{ }^{*}\right)^{\mathrm{f}}\right)\left(\mathrm{s}_{2}\right) \text {, for any } \mathrm{s}_{2} \varepsilon \mathrm{s}_{2} \text {. }
\end{aligned}
$$

Then UF $\varepsilon \mathrm{q}_{2}{ }^{*} \mathrm{~F}$ since $\mathrm{T}\left(\mu_{1}{ }^{\circ} \mathrm{q}_{1}{ }^{*}\right)$ f $\varepsilon \mathrm{F}$. Furthermore, $U: F \rightarrow \mathrm{q}_{2}{ }^{*} \mathrm{~F}$ is a positive linear operator of norm 1 since $\mu_{1}$ is a mean on $\mathrm{q}_{1}{ }^{*} \mathrm{~F}$.

Let $\mu_{2} \varepsilon \operatorname{LIM}\left(\mathrm{q}_{2}{ }^{\star} \mathrm{F}\right)$ and put $\mu=\mu_{2} \mathrm{U}$. Then $\mu \varepsilon \mathrm{F}^{*}, \mu(\mathrm{f}) \geq 0$ for each $\mathrm{f} \geq 0$ in $\mathrm{F}$, and $\mu(1)=1$. Thus $\mu$ is a mean on $F$.

We must show $\mu \varepsilon \operatorname{LIM}(F)$. Observe that for $s_{1} \varepsilon S_{1}, s_{2} \varepsilon S_{2}$,

$$
\begin{aligned}
& \mathrm{q}_{1}{ }^{*}\left(\mathrm{~L}_{\left(\mathrm{s}_{1}, 1\right)} \mathrm{L}_{\left(1, \mathrm{~s}_{2}\right)} \mathrm{f}\right)=\mathrm{q}_{1}{ }^{*}\left(\mathrm{~L}_{\left(1, \mathrm{~s}_{2}\right)\left(\mathrm{s}_{1}, 1\right)} \mathrm{f}\right) \\
& =q_{1}^{*}\left(L\left(\tau\left(s_{2}, s_{1}\right), s_{2}\right) f\right) \text {. }
\end{aligned}
$$

Furthermore, for any $g \varepsilon F, s_{1}, t_{1}, \varepsilon s_{1}$,

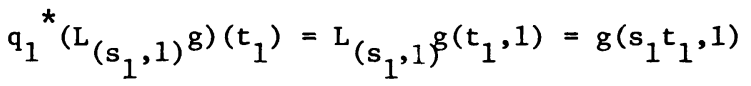

$$
\begin{aligned}
& \left.=\left(q_{1}{ }^{*} g\right)\left(s_{1} t_{1}\right)=L_{s_{1}}\left(q_{1}^{*} g\right)\left(t_{1}\right)\right) .
\end{aligned}
$$

Thus,

$$
\mathrm{q}_{1}{ }^{*}\left(\mathrm{~L}_{\left(\mathrm{s}_{1}, 1\right)} \mathrm{L}_{\left(1, \mathrm{~s}_{2}\right)} \mathrm{f}\right)=\mathrm{L}_{\mathrm{s}_{1}}\left(\mathrm{q}_{1}{ }^{*} \mathrm{~L}_{\left(1, \mathrm{~s}_{2}\right)} \mathrm{f}\right) .
$$


By (3.1) and (3.2) we obtain for $d \varepsilon D, s_{1} \varepsilon S_{1}$, $f \varepsilon F$,

$$
\begin{aligned}
& \left.\mu_{1}\left(q_{1}{ }^{*}\left(L_{(\tau}\left(d, s_{1}\right), d\right) f\right)\right)=\mu_{1}\left(q_{1}{ }^{*}\left(L_{\left(s_{1}, 1\right)}{ }^{L}(1, d) f\right)\right) \\
& =\mu\left(\mathrm{L}_{\mathrm{s}_{1}} \mathrm{q}_{1}{ }^{*}(\mathrm{~L}(1, \mathrm{~d}) \mathrm{f})\right)=\mu_{1}\left(\mathrm{q}_{1}{ }^{*}\left(\mathrm{~L}_{(1, \mathrm{~d})} \mathrm{f}\right)\right) \\
& =(U f)(d) \text {. }
\end{aligned}
$$

By the definition of $D$ and the continuity in the variable $s_{1}$ of the extreme left side of (3.3), we obtain,

$$
\mu_{1}\left(q_{1}{ }^{*}\left(L_{\left(s_{1}, d\right)} f\right)\right)=(\text { Uf })(d)\left(d \varepsilon D, s_{1} \varepsilon s_{1}\right) \text {. }
$$

Since $\bar{D}=S_{2}$ we therefore have

$$
\mu_{1}\left(q_{1}^{*}\left(L_{(}\left(s_{1}, s_{2}\right) \dot{r}\right)\right)=(U f)\left(s_{2}\right)\left(s_{1} \varepsilon s_{1}, s_{2} \varepsilon s_{2}\right) .
$$

That is,

$$
\mathrm{UL}_{\left(\mathrm{s}_{1}, 1\right)} \mathrm{f}=\mathrm{Uf}, \forall \mathrm{s}_{1} \varepsilon \mathrm{s}_{1} .
$$

Observe that for $s_{2}, t_{2} \in s_{2}$,

$$
\begin{aligned}
& U\left(L\left(1, s_{2}\right) f\right)\left(t_{2}\right)=\mu_{1}\left(q_{1}{ }^{*}\left(L\left(1, t_{2}\right) L\left(1, s_{2}\right) f\right)\right) \\
& =\mu_{1}\left(q_{1}^{*}\left(L_{\left(1, s_{2} t_{2}\right)} f\right)\right)=(U f)\left(s_{2} t_{2}\right) \\
& =\left(\mathrm{L}_{\mathrm{s}_{2}} \mathrm{Uf}\right)\left(\mathrm{t}_{2}\right) \text {. }
\end{aligned}
$$

Thus,

$$
\mathrm{U}\left(\mathrm{L}_{\left(1, \mathrm{~s}_{2}\right)} \mathrm{f}\right)=\mathrm{L}_{\mathrm{s}_{2}} \mathrm{Uf}, \mathrm{s}_{2} \varepsilon \mathrm{s}_{2} .
$$

By (3.4) and (3.5) we obtain for any $s_{1} \varepsilon S_{1}, s_{2} \varepsilon S_{2}$

$$
\begin{aligned}
& \left.\mu\left(L_{\left(s_{1}, s_{2}\right)} f\right)=\mu\left(L_{\left(1, s_{2}\right)}\right)_{\left(s_{1}, 1\right)}^{f}\right) \\
& =\mu_{2}\left[\mathrm{U}\left(\mathrm{L}\left(1, \mathrm{~s}_{2}\right)^{\mathrm{L}}\left(\mathrm{s}_{1}, 1\right) \mathrm{f}\right)\right] \\
& =\mu_{2}\left[\mathrm{~L}_{s_{2}} \mathrm{U}\left(\mathrm{L}\left(\mathrm{s}_{1}, 1\right) \mathrm{f}\right)\right] \\
& =\mu_{2}\left(L_{s_{2}} \text { Uf }\right)=\mu_{2} \text { (Uf) }=\mu(f) \text {. }
\end{aligned}
$$

Thus $\mu \varepsilon \operatorname{LIM}(\mathrm{F})$ and we are done.

The proof of (b) is done in an analogous manner and is, in fact, much easier. Choose any $\mu_{1} \in \operatorname{RIM}\left(\mathrm{q}_{1}{ }^{*} \mathrm{~F}\right)$ and for each $\mathrm{f} \varepsilon \mathrm{F}$, define (Uf) $\left(s_{2}\right)=\mu_{1}\left(q_{1}{ }^{*}\left(R\left(1, s_{2}\right) f\right)\right), s_{2} \varepsilon s_{2}$.

Then $\mathrm{U}: \mathrm{F} \rightarrow \mathrm{q}_{2}{ }^{*} \mathrm{~F}$ since $\mathrm{F}$ is right introverted. Furthermore, $\mathrm{U}: \mathrm{F} \rightarrow \mathrm{q}_{2}{ }^{*} \mathrm{~F}$ is a positive linear operator of norm 1 since $\mu_{1}$ is a mean on $q_{1}{ }^{*} \mathrm{~F}$. Let $\mu_{2} \varepsilon \operatorname{RIM}\left(q_{2}{ }^{*} \mathrm{~F}\right)$ 
and put $\mu=\mu_{2}$ U. Then $\mu$ is a mean on $F$ and we must show $\mu \varepsilon \operatorname{RIM}(F)$.

Observe that for any $s_{1}, t_{1} \varepsilon S_{1}, s_{2}, t_{2} \varepsilon S_{2}$, f $\varepsilon F$,

$$
\begin{aligned}
& \mathrm{q}_{1}{ }^{* \mathrm{R}}\left(1, \mathrm{t}_{2}\right)^{\mathrm{R}}\left(\mathrm{s}_{1}, \mathrm{~s}_{2}\right) \mathrm{f}\left(\mathrm{t}_{1}\right)=\mathrm{f}\left[\left(\mathrm{t}_{1}, 1\right)\left(1, \mathrm{t}_{2}\right)\left(\mathrm{s}_{1}, \mathrm{~s}_{2}\right)\right] \\
& =f\left[\left(t_{1} \tau\left(t_{2}, s_{1}\right), t_{2} s_{2}\right)\right] \\
& =f\left[\left(t_{1} \tau\left(t_{2}, s_{1}\right), 1\right)\left(1, t_{2} s_{2}\right)\right]
\end{aligned}
$$

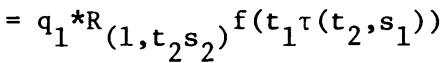

$$
\begin{aligned}
& =R_{\tau\left(t_{2}, s_{1}\right) q_{1} * R}\left(1, t_{2} s_{2}\right) f\left(t_{1}\right) \text {. }
\end{aligned}
$$

Thus, $q_{1}{ }^{*}\left(1, t_{2}\right)^{R}\left(s_{1}, s_{2}\right) f=R_{\tau\left(t_{2}, s_{1}\right) q_{1} * R\left(1, t_{2} s_{2}\right)}$, and therefore since $\mu_{1} \varepsilon \operatorname{RIM}\left(\mathrm{q}_{1} * \mathrm{~F}\right)$,

$$
\begin{aligned}
& U\left(R_{\left(s_{1}, s_{2}\right)} f\right)\left(t_{2}\right)=\mu_{1}\left(q_{1} *_{\left(1, t_{2}\right)}{ }^{R}\left(s_{1}, s_{2}\right) f\right) \\
& =\mu_{1}\left(R_{\tau\left(t_{2}, s_{1}\right)} q_{1} * R\left(1, t_{2} s_{2}\right) f\right)=\mu_{1}\left(q_{1} * R\left(1, t_{2} s_{2}\right) f\right) \\
& =R_{s_{2}} \operatorname{Uf}\left(t_{2}\right) .
\end{aligned}
$$

Then,

$$
\begin{gathered}
\mu\left(R_{\left(s_{1}, s_{2}\right)} f\right)=\mu_{2}\left[U\left(R\left(s_{1}, s_{2}\right) f\right)\right]=\mu_{2}\left(R_{s_{2}} U f\right) \\
=\mu_{2}(U f)=\mu(f) .
\end{gathered}
$$

Hence $\mu \varepsilon \operatorname{RIM}(F)$ and we are done.

4. Application to $\mathrm{K}\left(\mathrm{S}_{1} \bigcirc \mathrm{s}_{2}\right)$ WAP

Let $\mathrm{S}$ be a semitopological semigroup and let SAP(S) denote the closed 1inear span in $\mathrm{C}(\mathrm{S})$ of the coefficients of all finite-dimensional continuous unitary representation of $\mathrm{S}$. SAP(S) is called the space of strongly almost periodic functions on $S$. Let $\operatorname{WAP}(S)=\left\{f \in C(S): R_{S} f\right.$ is relatively weakly compact $\}$. WAP $(S)$ is called the space of weakly almost periodic functions on S. (See Berglund, Junghenn and Milnes (6) for properties of SAP(S), WAP(S)).

In (3) it was shown that if $\mathrm{S}_{1}, \mathrm{~S}_{2}$ are semitopological semigroups with identities then

$$
\left(\mathrm{S}_{1}\left(\mathrm{~S}_{2}\right)^{\mathrm{SAP}}=\mathrm{x} \odot \mathrm{s}_{2}{ }^{\mathrm{SAP}}\right.
$$

where $\left(\mathrm{s}_{1}(\tau) \mathrm{s}_{2}\right)$ SAP and $\mathrm{s}_{2}$ SAP are the canonical SAP-compactifications of $\mathrm{s}_{1}(\mathcal{}) \mathrm{s}_{2}$ and $S_{2}$ respectively, $\mathrm{X}$ is a compact topological group which is a homomorphic image 
of the canonical SAP-compactification of $\mathrm{s}_{1}$, and equality denotes canonical isomorphism.

We now prove the following lemma which shall be used in the decomposition of the kernel.

LEMMA. 4.1 Let $S$ be a semitopological semigroup such that WAP(S) is amenable. Let $\left(S^{\text {WAP }}, \Psi\right)$ be a WAP-compactification of $S, \xi$ the identity of $\mathrm{K}\left(\mathrm{S}^{\mathrm{WAP}}\right), \rho_{\xi}$ : $S^{\mathrm{WAP}} \rightarrow \mathrm{K}\left(\mathrm{S}^{\mathrm{WAP}}\right)$ be right multiplication. Then $\left(\mathrm{K}\left(\mathrm{S}^{\mathrm{WAP}}\right), \rho_{\xi} \Psi\right)$ is an SAP-compactification of $\mathrm{S}$.

PROOF. Since WAP $(\mathrm{S})$ is amenable, $\mathrm{K}\left(\mathrm{S}^{\mathrm{WAP}}\right)=\mathrm{S}^{\mathrm{WAP}} \xi$ and is a compact topological group (deLeeuw and Glicksberg $(7)$ ). Then $\rho_{\xi}$ maps $S^{\text {WAP }}$ onto $K\left(S^{\text {WAP }}\right.$ ) and $\rho_{\xi} \Psi: S \rightarrow K\left(S^{W A P}\right)=S^{\text {WAP }} \xi$ is a continuous homomorphism with range dense in $\mathrm{S}^{\mathrm{WAP}} \xi$. Observe that $\left.\rho_{\xi}\right|_{\mathrm{K}}\left(\mathrm{S}^{\mathrm{WAP}}\right)$ is the identity mapping on $\mathrm{K}\left(\mathrm{S}^{\mathrm{WAP}}\right)$. Let $\left(S^{S A P}, \gamma\right)$ be the canonical SAP-compactification of $S$. By the universal mapping property of SAP and WAP compactifications, there exist continuous homomorphisms $\Phi$ and $\theta$ such that $\Phi: S^{S^{S A P}} \rightarrow K\left(S^{W A P}\right), \theta: S^{W A P} \rightarrow S^{S A P}$ and $\Phi \gamma=\rho_{\xi} \Psi, \theta \Psi=\gamma$. Observe further that since $\Phi \theta \Psi=\rho_{\xi} \Psi$, then $\Phi \theta=\rho_{\xi}$ by the continuity of $\Phi \theta, \rho_{\xi}$ and the fact that $\overline{\Psi(S)}=s^{\text {WAP }}$.

All of the above relations are illustrated in the following commutative diagram:

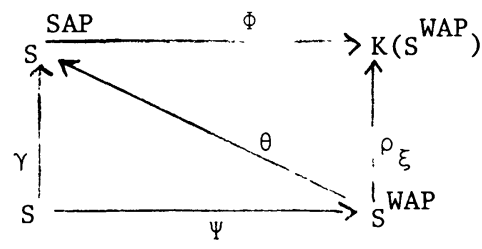

It suffices to show that $\Phi$ is one-to-one so that $\mathrm{K}\left(\mathrm{S}^{\mathrm{WAP}}\right)$ will be an SAPcompactification of $\mathrm{S}$. Let $\mathrm{y}_{1}, \mathrm{y}_{2} \varepsilon \mathrm{S}^{\mathrm{SAP}}$. Then there exist $\mathrm{x}_{1}, \mathrm{x}_{2} \varepsilon \mathrm{S}^{\text {WAP }}$ such that $\theta\left(\mathrm{x}_{1}\right)=\mathrm{y}_{1}$ and $\theta\left(\mathrm{x}_{2}\right)=\mathrm{y}_{2}$. Suppose $\Phi\left(\mathrm{y}_{1}\right)=\Phi\left(\mathrm{y}_{2} \cdot\right.$. Then $\Phi\left(\theta\left(\mathrm{x}_{1}\right)\right)=\Phi\left(\theta\left(\mathrm{x}_{2}\right)\right)$. Since $\mathrm{S}^{\mathrm{SAP}}$ is a compact topological group and $\theta(\xi)$ is an idempotent in $\mathrm{S}^{\mathrm{SAP}}$, $\theta(\xi)$ is the identity of $\mathrm{s}^{\mathrm{SAP}}$. Thus $\theta\left(\mathrm{x}_{i}\right)=\theta\left(\mathrm{x}_{\mathbf{i}}\right) \theta(\xi)=\theta\left(\mathrm{x}_{i} \xi\right)(\mathbf{i}=1,2)$, so $\Phi\left(\theta\left(x_{1} \xi\right)\right)=\Phi\left(\theta\left(x_{2} \xi\right)\right)$. On the other hand, 


$$
\Phi\left(\theta\left(x_{i} \xi\right)\right)=\rho_{\xi}\left(x_{i} \xi\right)=x_{i} \xi(i=1,2),
$$

so, $x_{1} \xi=x_{2} \xi$, and hence $y_{1}=\theta\left(x_{1} \xi\right)=\theta\left(x_{2} \xi\right)=y_{2} \cdot / /$

We shall use the relation (4.1), the above lemma and the results in the following discussion to establish conditions under which we may express

$\mathrm{K}\left[\left(\mathrm{S}_{1} \text { ( ) } \mathrm{S}_{2}\right)^{\mathrm{WAP}}\right]$ as a semidirect product

$$
\mathrm{K}\left[\left(\mathrm{S}_{1} \text { (T) } \mathrm{S}_{2}\right)^{\mathrm{WAP}}\right]=\mathrm{x} \bigodot \mathrm{K}\left(\mathrm{s}_{2}{ }^{\mathrm{WAP}}\right)
$$

where equality denotes canonical isomorphism and $\mathrm{X}$ is a compact topological group.

We shall assume that $\operatorname{WAP}\left(\mathrm{S}_{1}\right)$ and $\operatorname{WAP}\left(\mathrm{S}_{2}\right)$ are amenable. By (deLeeuw and Glicksberg (7), Lemma 5.2) since $q_{i}: S_{i} \rightarrow S_{1}$ (T) $S_{2}$ is a continuous homomorphism for

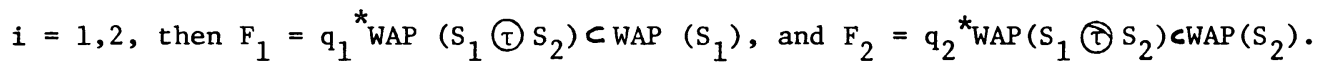
(In fact, equality holds in the latter.) Thus, $\mathrm{q}_{1}{ }^{*} \mathrm{WAP}\left(\mathrm{s}_{1}\left(\mathrm{~T} \mathrm{~s}_{2}\right)\right.$ and $\mathrm{q}_{2}{ }^{*} \mathrm{WAP}\left(\mathrm{S}_{1}\right.$ ( $\left.) \mathrm{s}_{2}\right)$ are amenable and if we assume $D=\left\{s_{2} \varepsilon S_{2}: \tau \overline{\left(s_{2}, S_{1}\right)}=S_{2}\right\}$ is dense in $s_{1}$, then $\operatorname{WAP}\left(\mathrm{S}_{1}\right.$ (T) $\left.\mathrm{S}_{2}\right)$ is amenable by Theorem 3.1 .

By $\left((7)\right.$, Theorem 4.11) $\mathrm{K}\left[\left(\mathrm{S}_{1} \text { (T) } \mathrm{S}_{2}\right)^{\mathrm{WAP}}\right]$ and $\mathrm{K}\left(\mathrm{S}_{2}{ }^{\mathrm{WAP}}\right)$ are compact topological groups. Furthermore, by Lemma $4.1, \mathrm{~K}\left[\left(\mathrm{~S}_{1}\left(\mathcal{} \mathrm{S}_{2}\right)^{\mathrm{WAP}}\right]\right.$ is a SAP-compactification of $\mathrm{S}_{1}\left(\mathrm{~S}_{2}\right.$, and $\mathrm{K}\left(\mathrm{S}_{2}{ }^{\mathrm{WAP}}\right.$ ) is a SAP-compactification of $\mathrm{S}_{2}$ (symbollically denoted by $\mathrm{K}\left[\left(\mathrm{S}_{1}\left(\mathrm{~T} \mathrm{~S}_{2}\right)^{\mathrm{WAP}}\right]=\left(\mathrm{S}_{1}\left(\mathrm{~T} \mathrm{~S}_{2}\right)^{\mathrm{SAP}}\right.\right.$, and $\mathrm{K}\left(\mathrm{S}_{2}{ }^{\mathrm{WAP}}\right)=\mathrm{S}_{2} \mathrm{SAP}$, respectively, where equality denotes canonical isomorphism). Thus, we have proved the following

PROPOSITION 4.2 Let $\mathrm{S}_{1}, \mathrm{~S}_{2}$ be semitopological semigroups with identities and $\mathrm{S}_{1}$ ( ) $\mathrm{S}_{2}$ a semidirect product. Suppose $\operatorname{WAP}\left(\mathrm{S}_{1}\right)$, $\operatorname{WAP}\left(\mathrm{S}_{2}\right)$ are amenable, and

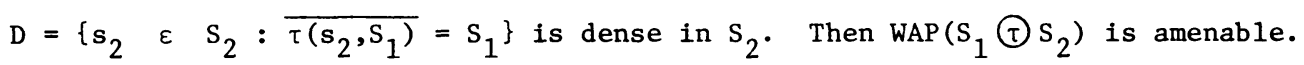
Furthermore, we may represent $\mathrm{K}\left[\left(\mathrm{S}_{1} \text { (T) } \mathrm{S}_{2}\right)^{\mathrm{WAP}}\right]$ as a semidirect product $\mathrm{K}\left[\left(\mathrm{S}_{1} \text { (T) } \mathrm{S}_{2}\right)^{\mathrm{WAP}}\right]=\mathrm{X} \bigodot \mathrm{K}\left(\mathrm{S}_{2}{ }^{\mathrm{WAP}}\right)$, where equality denotes canonical isomorphism, $\left(\mathrm{S}_{1}(\mathrm{\tau}) \mathrm{S}_{2}\right)$ WAP and $\mathrm{s}_{2}{ }^{\mathrm{WAP}}$ are canonical WAP-compactifications of $\mathrm{S}_{1}$ (T) $\mathrm{s}_{2}$ and $\mathrm{s}_{2}$ respectively, and $\mathrm{X}$ is a compact topological group which is a continuous homomorphic image of the canonical SAP-compactification of $\mathrm{s}_{1} \cdot / /$

ACKNOWLEDGEMENT. This work was supported by a U. S. Naval Academy Research Council Grant.

The author wishes to thank the referee for suggesting several improvements to the exposition of the paper. 


\section{REFERENCES}

1. BERGLUND, J. F. and HOFMANN, K. H., Compact Semitopological Semigroups and Weakly Almost Periodic Functions, Lecture Notes in Math., vo1. 42, SpringerVerlag, Berlin, 1967.

2. LERNER, B.T., C* - Algebra Compactifications of Semidirect Products of Semitopological Semigroups, Dissertation, Geo. Wash. Univ., Wash., D.C., 1979.

3. JUNGHENN, H. D. and LERNER, B.T., Semigroup Compactifications of Semidirect Products, Trans. Amer. Math. Soc., 265 (1981), 393-404.

4. JUNGHENN, H.D., C* - Algebras of Functions on Direct Products of Semigroups, Rocky Mountain J. of Math., 10(3) (1980), 589-597.

5. JUNGHENN, H.D., Topological Left Amenability of Semidirect Products, Canad. Math. Bu11., 24 (1) (1981), 79-85.

6. BERGLUND, J.F., JUNGHENN, H.D., and MILNES, P., Compact Right Topological Semigroups and Generalization of Almost Periodicity, Lecture Notes in Math., vol. 663, Springer-Verlag, Berlin, 1978.

7. delEEUW, K., and GLICKSBERG, I., Applications of Almost Periodic Compactifications Ac ca. Math., 105(1961), 63-97. 


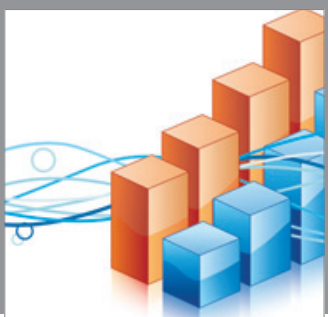

Advances in

Operations Research

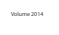

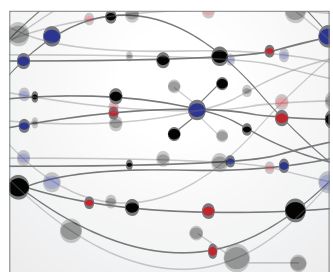

\section{The Scientific} World Journal
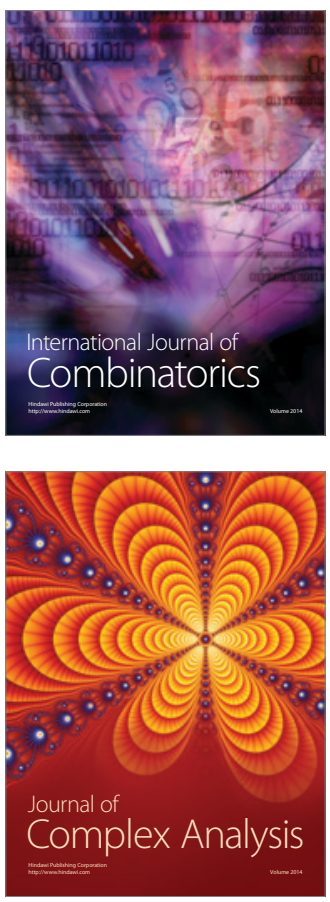

International Journal of

Mathematics and

Mathematical

Sciences
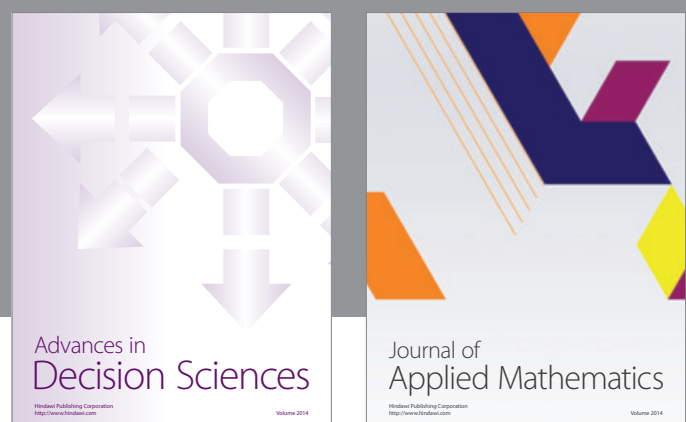

Journal of

Applied Mathematics
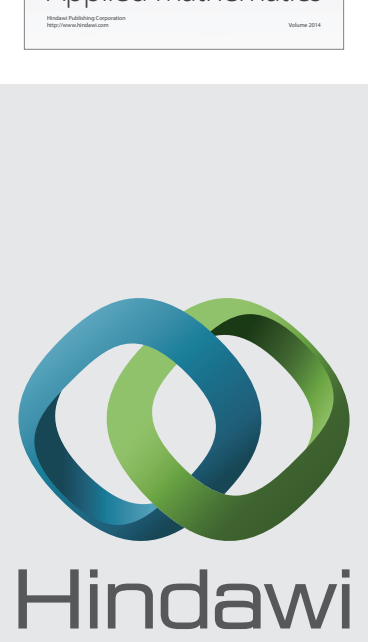

Submit your manuscripts at http://www.hindawi.com
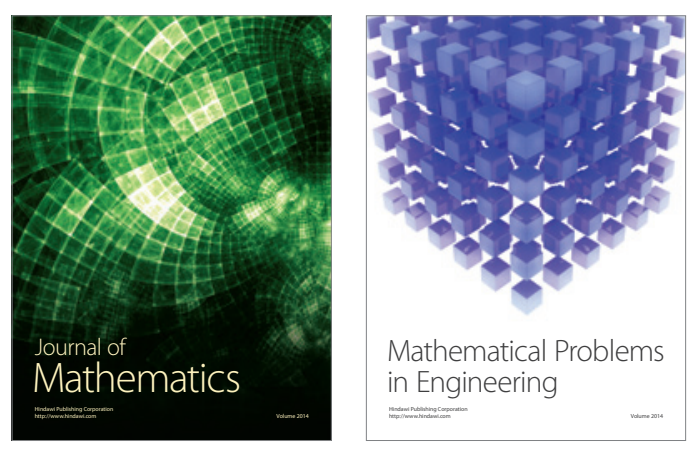

Mathematical Problems in Engineering
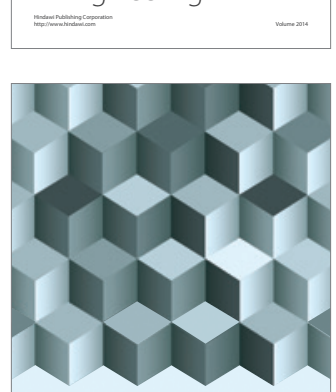

Journal of

Function Spaces
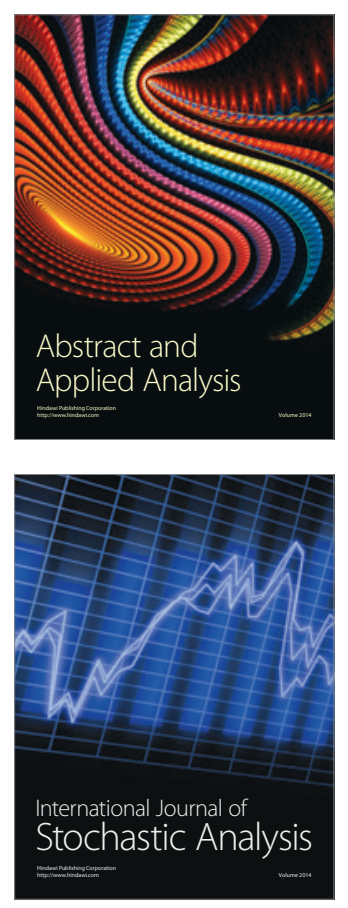

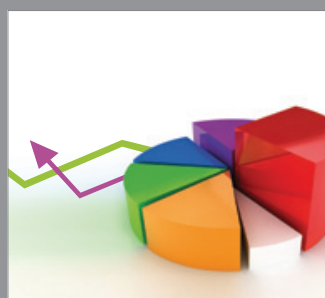

ournal of

Probability and Statistics

Promensencen
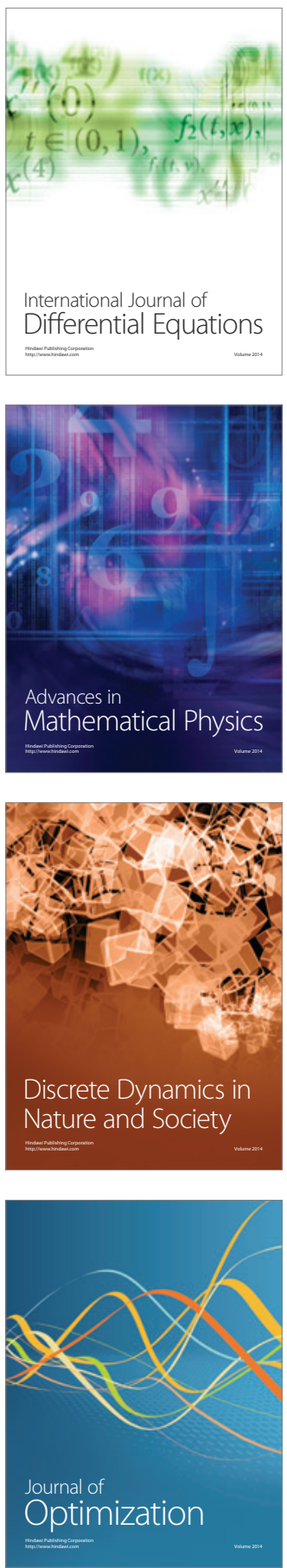